\title{
Martin Sabrow, Die Zeit der Zeitgeschichte
}

Göttingen : Wallstein Verlag, 2012, 38 p., 10,20€

\section{Marie-Bénédicte Vincent}

\section{Q OpenEdition}

\section{Journals}

Édition électronique

URL : http://journals.openedition.org/ifha/8168

DOI : 10.4000/ifha.8168

ISSN : 2198-8943

Éditeur

IFRA - Institut franco-allemand (sciences historiques et sociales)

Référence électronique

Marie-Bénédicte Vincent, « Martin Sabrow, Die Zeit der Zeitgeschichte », Revue de l'IFHA [En ligne], Date de recension, mis en ligne le 14 avril 2015, consulté le 22 septembre 2020. URL : http:// journals.openedition.org/ifha/8168; DOI : https://doi.org/10.4000/ifha.8168

Ce document a été généré automatiquement le 22 septembre 2020

CIFHA 


\title{
Martin Sabrow, Die Zeit der Zeitgeschichte
}

Göttingen : Wallstein Verlag, 2012, 38 p., 10,20€

\author{
Marie-Bénédicte Vincent
}

Le «temps de la Zeitgeschichte» est la version écrite de la leçon inaugurale de Martin Sabrow à l'Université Humboldt en 2010. Ce petit essai, à mi-chemin entre épistémologie et vulgarisation, a son intérêt en ce qu'il expose une vision de la discipline qui conserve ses spécificités en Allemagne. En effet, la Zeitgeschichte n'est ni l'histoire contemporaine française, contrairement à ce qu'affirme la première page, ni l'histoire du temps présent, qui en France recouvre le segment de l'histoire dont il reste des témoins. M. Sabrow étend le champ de la Zeitgeschichte aux périodes vivantes de la mémoire collective (référence est faite à Maurice Halbwachs) même après la disparition des témoins directs.

Selon lui, la Zeitgeschichte recouvre un triple rapport au temps, ce qui fournit la structure de l'opuscule. La première partie s'interroge, classiquement, sur l'époque traitée par la Zeitgeschichte et ses bornes chronologiques. L'auteur montre que la définition qu'avait donnée en 1953 Hand Rothfels (de 1917 à 1945) n'est plus valable : la Zeitgeschichte a aujourd'hui délaissé la Première Guerre mondiale et la République de Weimar. Par ailleurs, même si le nazisme concentre toujours l'attention des historiens, la focale s'est déplacée de 1933 au génocide des juifs. La Zeitgeschichte ne s'occupe donc pas d'une période définie a priori. Si certains historiens contournent la difficulté en définissant des sous-périodes (1917-1945, 1945-1989, l'après-1989), ils manquent la spécificité épistémologique de la discipline, qui est non pas de produire des découpages chronologiques, mais d'inclure des témoignages. Cette autorité des témoignages - $\mathrm{M}$. Sabrow parle de memorial turn - s'explique souvent par la non-ouverture des archives, mais va au-delà : en témoigne l'utilisation des témoignages de "seconde génération ", par exemple ceux des descendants des victimes dans l'histoire de l'holocauste. On peut ainsi concevoir une Zeitgeschichte discontinue du point de vue chronologique, une période restant dans la Zeitgeschichte aussi longtemps que perdurent la force des souvenirs collectifs et l'intensité du débat public à son endroit. Une seconde spécificité 
distingue la Zeitgeschichte de «l'histoire du présent » (histoire immédiate en France) : la première a besoin de points d'observation, - de Sehe-punkte (par exemple 1945, 1973, 1989) - à partir desquels l'historien travaille sur des séquences closes, ce qui rend possible la saisie intellectuelle et l'interprétation. Avec ces critères, M. Sabrow circonscrit le temps de la Zeitgeschichte des années 1930 à la chute du Mur. Il va sans dire que les bornes chronologiques seraient différentes en France.

La deuxième partie, moins épistémologique (et moins percutante), montre que la Zeitgeschichte s'intéresse aussi à la représentation du temps propre à chaque époque. M. Sabrow distingue à nouveau la Zeitgeschichte du présent, qui est caractérisé par une accélération du temps (la référence est ici le travail de Hartmut Rosa sur l'accélération sociale au $\mathrm{xx}^{\mathrm{e}}$ siècle). Il analyse surtout les conceptions du temps déployées par les régimes nazi et communiste: les deux dictatures allemandes ont développé des cultures temporelles opposées bien qu'elles aient été toutes deux sous-tendues par des eschatologies. Mais la démonstration n'est qu'esquissée.

Enfin, la troisième partie porte sur les conditions de réception de la Zeitgeschichte dans la société actuelle : peut-elle répondre à la très large demande sociale d'histoire et trouver sa place au sein d'une culture mémorielle omniprésente ? La grande popularité dont jouit la Zeitgeschichte, qui contraste avec son difficile établissement académique après 1945, s'explique par le fait que les contemporains la considèrent comme ressource pour définir leur identité. M. Sabrow exhorte donc la Zeitgeschichte à ne pas s'enfermer dans la tour d'ivoire universitaire, mais à s'insérer dans le paysage médiatique pour y apporter la réflexion théorique qui manque le plus souvent dans le rapport de la société à son passé. Ainsi à propos du débat soulevé par l'exhumation de la thèse d'habilitation du président de la Humboldt-Universität élu en 2010, J.-H. Olbertz : rédigée début 1989, la thèse apparaît aujourd'hui scandaleusement imprégnée de vulgate marxiste. Or l'historien ne doit-il pas s'abstenir de jugement moral et mettre à distance un tel texte en lui rendant son statut d'objet du passé (tout en conservant l'approche critique)? M. Sabrow engage la Zeitgeschichte à être résolument de son temps, tout en maintenant sa capacité autoréflexive, gage de scientificité.

$\mathrm{Au}$ total, certaines affirmations de l'auteur appellent certainement des nuances (ainsi sur le prétendu déclin d'intérêt pour la Première Guerre mondiale et l'entre-deuxguerres), mais le livre a le mérite d'inviter à la réflexion, en commençant par la comparaison avec la France.

INDEX

Index chronologique : Époque contemporaine

Thèmes : Historiographie/ Méthodologie 
AUTEUR

MARIE-BÉNÉDICTE VINCENT

ENS, Paris 